\title{
Erratum to: Four Papers Published in the Journal of Elasticity (2015) 119(1-2)
}

\author{
Roger Fosdick ${ }^{1} \cdot$ Eliot Fried $^{2}$
}

Published online: 21 May 2015

(C) Springer Science+Business Media Dordrecht 2015

\section{Erratum to: J Elast (2015) 119:23-34 \\ DOI 10.1007/s10659-014-9489-y}

The translation of Wunderlich's article "Über ein abwickelbaresMöbiusband", which appeared in the Monatshefte für Mathematik 66 (1962), 276-289, was undertaken with the kind permission of Springer, its publisher.

\section{Erratum to: J Elast (2015) 119:19-22}

\section{DOI 10.1007/s10659-014-9491-4}

This article was originally published in German in Jahresbericht der Deutschen Mathematiker-Vereinigung 39 (2. Abt. Heft 5/8, Jahresversammlung vom 16. bis 23. September), 4951 (1929) and has been published in English with kind permission of the current editor in chief of this journal and the Deutschen Mathematiker-Vereinigung.

Erratum to: J Elast (2015) 119:3-6

DOI 10.1007/s10659-014-9490-5

There are instances where we have been unable to trace or contact the copyright holder of the translated articles. If notified the publisher will be pleased to rectify any errors or omissions at the earliest opportunity.

The online version of the original articles can be found under doi:10.1007/s10659-014-9489-y, doi:10.1007/s10659-014-9491-4, doi:10.1007/s10659-014-9490-5, doi:10.1007/s10659-014-9492-3.

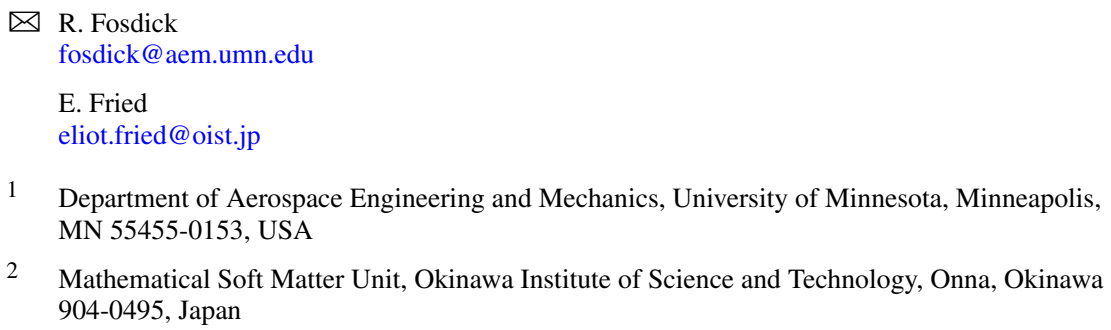




\section{Erratum to: J Elast (2015) 119:7-17 \\ DOI 10.1007/s10659-014-9492-3}

There are instances where we have been unable to trace or contact the copyright holder of the translated articles. If notified the publisher will be pleased to rectify any errors or omissions at the earliest opportunity. 